\title{
Contents and the language used in graffiti: A case of Kathmandu Valley
}

\author{
Jagadish Paudel and Pratiksha Neupane \\ Tribhuvan University, Nepal
}

\begin{abstract}
Graffiti is prevalent in modern cities across the world. It represents a range of issues and ideas, and its meaning can be interpreted socially, culturally, and politically. It features distinct forms of language. Using Multimodal Discourse Analysis (MDA) approach, this study analyses the contents, language and linguistic features of 44 graffiti arts found in the Kathmandu Valley to interpret the meanings of the graffiti. The results of this study reveal multiple issues such as culture, politics, gender discrimination and violence against women. The use of language and linguistics in the graffiti seems distinct in terms of word choice, syntactic structure, and rhetorical devices. It was found that the graffitists used multiple modes such as sign, symbol, color, words with images and stylish writing structures. The study will be of great importance to the researchers who want to analyze the language of graffiti and interpret the meanings they denote and to contribute to the body of existing literature on linguistic studies of graffiti. It is also useful for course designers and educators as they can incorporate graffiti in the courses and use them as resource materials in the classroom.
\end{abstract}

Keywords: Graffiti, contents, language and linguistics aspects, meanings, the Kathmandu Valley

\section{Introduction}

Graffiti is the scribble writing found on the wall of public places and buildings (Suliman, 2014). For Chiluwa (2008), graffiti is " any form of writing or images on the walls or surfaces of public buildings, parks, toilets, buses or trains, usually bearing some political or sexual contents, a lover's pledge, proposition, or obscene words" (p. 274); it includes any scribble writing, picture, painting or communicative expressions occurring in a public space. It exists in many forms such as paintings, drawings or alphabetical writings used to communicate socio-cultural and political messages. Rubdy (2015) writes "Graffiti is seen as representing either acts of resistance towards middle class norms and rejection of mainstream society, or attempts to overthrow hierarchy" (p. 280). In the same way, Farnia (2014) states that graffiti is the media which people employ to make their voice public, to express their annoyance, share thoughts, affection, personal announcements, political declarations, or even outcries of pain. Graffiti has also 
been taken by scholars as a "freedom of expression" (Tracy, 2005, p. 22) as graffitists' identities are most often kept anonymous. Graffiti is considered as a symbol of revolt against societal authorities, and even an act of destruction that must be amended (Nwoye, 1993). The public sometimes cannot freely express their individual voices due to social norms and personal restrictions (Abel \& Buckley, 1977) so they use graffiti writing as a means to voice their suppressed feelings, attitudes, interests and proscriptions.

Generally, graffiti and street art are taken as synonymous, but Collins (2018) has differentiated between the two. Collins writes "graffiti is used to describe a work that is done illegally, while street arts is typically used to describe a work that has been done with the property owner's permission" (p. 6). Nakarmi (2017) argues that any painting or scribbling done on the streets with permission is not considered graffiti, but mural art. In general, graffiti is taken as an illegal act which is usually drawn on public places.

Graffiti is multimodal in its form. It involves creating and conveying a message by using different modes of communication such as language, color, sign, symbol, image etc. And such creation has a huge potential for expressing cultural, political and social significance through its artistic nature. It has a high degree of demonstrative visual power for speaking out a political, gender, social and cultural issues, because it can portrait messages clearly in a stylish and artistic manner in public spaces. Instead of words, graffiti artists have turned tosymbols, color, signs and art images to express themselves in communication. And, graffiti means applying different modes of communication, stylish use of letters and other symbols where one can write anything one wants on walls. In a single graffiti, different forms of semiotic resources such as image, language and space have been combined, which contributes to communicate a meaningful message more clearly to the intended audiences.

Graffiti art is found nearly everywhere in modern cities (Brett, 2011). In Nepal too, graffiti has been a new trend to pass messages regarding political, cultural and social changes by employing various semiotic resources. If we go around to different crowded places of the Kathmandu Valley, we observe various images and stylized writings on the wall of streets and other public places. Graffiti has been adopted as a form of protest. Writing on the walls via the use of semiotic resources can make an audience universalize themes of gender, politics and religion (Liechty, 2003) in an exciting, immediate way and through a very specific cultural lens of the local subculture (Minchin, 2016). Similar to what Liechty describes, there are many different graffiti that appear in public places of the Kathmandu valley, dealing with the subject of women and violence, politics, environment and more, all of which help people to understand the socio-cultural issues of today's society in the country.

This study will be valuable for analyzing languages used in the graffiti and significant in revealing great information about the psychology of the graffitists. Moreover, if it is used as a teaching resource in the classroom, it might be useful for fostering students' noticing, identifying critical and creative capacity. So, it is useful for course designers and educators as they can include graffiti in their courses and use them as resource materials in the classroom. Teachers and 
students can learn analytical capacity lookingat socio-cultural and sociopolitical aspects like cultures, costumes and languages represented in graffiti images. Furthermore, this research will be significant to fill up research gap in the field of the Nepalese graffiti as we can hardly see any research in the area. Similarly, this research will be supportive for street artists and graffiti writers to provide evidence of graffiti practiced on public spaces. Further, this study will be highly useful for the researchers who are interested in analyzing the language of graffiti and interpret the meanings they convey and contribute to the body of existing literature on linguistic studies.

\section{The context}

Graffiti arts are pervasive in every major city in today's world, and here in Kathmandu as well, significant graffiti is found in public places. If anyone travels around the Kathmandu valley, s/he can find excessive use of wall writing and graffiti in nearly all public places. In a real sense, graffiti is largely regarded as an illegal art; however, it is also relatively known for its artistic techniques (Stampoulidis, 2016). What is more, the visibility of graffiti in most cites indicates that graffiti is an important medium of communication.Today, the trend of graffiti writing as a medium of public communication is widely established in the Nepalese culture. The Nepalese graffitists have started to employ a number of semiotics forms (signs, color, and pictures) along with artistic combination of words. And, as Nepal is a multilingual country, it is also found that the mixed language scribbles and translation of the languages in graffiti writings.
Although graffiti is commonly found throughout the Kathmandu Valley, hitherto, to our knowledge, no studies has been executed to analyze the content, language and linguistics of features of graffiti in Nepal; therefore, a gap can be clearly seen in the current state of graffiti research. The visibility of graffiti in the Kathmandu Valley and the dearth of research in the graffiti in Nepal motivated us to carry out this research to explore the content represented in the graffiti and to identify distinct language and linguistics features of the graffiti as well as to decipher their meanings in the Nepali context.

\section{An analytical framework of MDA}

The analytical approach of MDA is categorized into 6 different parts which provide a basis to analyze the collected graffiti:

\section{Thematic content representation of graffiti}

Thematic content analysis of graffiti helps us to analyze the graffiti images from different themes based on their content. It is useful for the researcher to classify the "raw" data in meaningful concepts and then group them into relevant all-encompassing categories in order to examine the main prevalent themes and contextual meanings of graffiti (Al- khawaldeh, Khawaldeh, Bani-Khair and Khawaldeh, 2017). While analyzing the representation of graffiti from its content, different linguists reveal some specific themes. Mwangi (2012) examined the graffiti written by students in his research study where he found that 
students used various communicative functions such as humor, symbolism, irony, short films, acronyms and abbreviation in their graffiti writings. Likewise, in their research, Sad and Kutlu (2009) also examined some themes of graffiti-writing such as gender, politics, religious communication, humor, sexual content, and romance. All these themes offer ideas to analyze graffiti found in the Kathmandu Valley, and it may even offer educators real opportunities to use graffiti content in classroom teaching for interactive classroom learning.

\section{Graffiti as a form of multimodality}

Multimodality refers to the multiple modes which help us to understand the creation of graffiti and provide us the possibility of finding meaning in different forms. AsBhusal (2019), a multimodal theory scholar, states, "Multimodality refers to multiple modes of communication - textual, aural, visual, and spatial" (p. 167). Graffiti is a form of multi-modality which symbolizes meaning through a combination of different semiotic resources. To support this notion, Kress and Leeuwen (2006, p. 15) have introduced three meaningmaking principles.

To use Halliday's terms, everysemiotic fulfils both an 'ideational' function, a function of representing 'the world aroundand inside us' and an 'interpersonal' function, a function of enacting social interactions associal relations. All message entities - texts - also attempt to present a coherent 'world ofthe text', what Halliday calls the 'textual' function - a world in which all the elements ofthe text cohere internally, and which itself coheres with its relevant environment. Whetherwe engage in conversation, produce an advertisement or play a piece of music, we aresimultaneously communicating, doing something to, or for, or with, others in the here andnow of a social context (swapping news with a friend; persuading the reader of a magazineto buy something; entertaining an audience) and representing some aspect of the world'out there', be it in concrete or abstract terms (the content of a film we have seen; thequalities of the advertised product; a mood or melancholy sentiment or exuberant energyconveyed musically), and we bind these activities together in a coherent text or communicative event.

Graffitists uses multimodal semiotic resources in the meaning-making process. They create the meaning with varying combinations of multiple resources. So, Alshreif (2016) claims that the creators of graffiti are also the creators of meaning. Thus, varied semiotic resources play a significant role in graffiti which interact complex social and cultural meaning in the society.

\section{Modes of communication}

Modes refer to meaning-making materials. Modes are not just the repetition of the same thing done differently; rather it allows to do somewhat different things in relation to the same thing, allowing us to combine the things to create richer meanings. In 
communication, different modes are used such as languages, signs, symbols, color, audio, video, gestural marks, pictures, images etc. According to Norris (2004), the conceptual framework of MDA allows for the integrations of all noticeable modes of communication performed by social actors. Norris further writes, "modes of communication interact heuristically for meaning-making process" (p. 104). When modes are in meaning-making process, they produce multiple meanings. Graffiti discourse is also produced by different social actors combined with multiple modes of communication. To maintain the idea of Kress and Leeuwen (1996), Machin (2016) insists that the significance of discourse is not only brought up through language but also through visual features and elements such as image, color and even through materials and objects. Graffiti writers often use these features in the meaning-making process. According to Scollon and Levine (2004, p. 3) "discourse is inherently multimodal, not mono-modal". And graffiti is considered as a discourse where different modes of communication are intricated by the social actors (Young, 2006; and Litossitti, 2006). Graffiti provides an explicit image and insightful understanding of social issues and identity through its multiple modes of communication which combine different kinds of semiotic resources.

\section{Socio-political meaning in graffiti}

Graffiti is taken asa reflection of society as it shows socio-political situation of the society. There are many different instances of graffiti that deal with the content of social and political issues. Scribbling graffiti on public places is a powerful strategy of graffitists sincethey can communicate social issues like politics dispute, gender issue, environmental problem etc. by the graffiti. And, in order to communicate socio-political messages effectively and differently, they scribble graffiti by combining of images, colors, languages, signs, and symbols. Mwangi (2015, p.19) says "in modern era graffiti have been used as a mode to pass socio-political messages in an artistic form". Graffitists can use their graffiti to push their agendas, or generally to make their presence felt, for it is extremely easy means of communicating ideas with the masses. Overall, graffiti incorporates various purposive meanings, symbolic meanings, gender meanings, and identity-related and political-meanings that are of public concern.

\section{Graffiti as a form of linguistic landscape (LL)}

The language used in the public spaces cannot be ignored.The language used in graffiti manifests power of language for communication, value and lifestyles of the people. As pointed out by Gorter (2006) LL is not only "the literal study of the languages as they are used in the signs", but also "the representation of the languages" of which the further aspect can be related to identity and cultural globalization, to the growing presence of English and to revitalization of minority language (p. 1).Thus, LL refers to the linguistic object that marks the public spaces. It allows people to 
point out the patterns of language and script represented in different ways on public spaces. LL has function of both information and symbolic marker where it can describe the language of a specific community and can communicate relative power and status of the community. As the Kathmandu Valley is linguistically diversified city, graffiti scribbled on the wall of public places often containlinguistic as well as scripture variations. That is, multilingualism can be observed in the graffiti writing in the valley.

Graffiti has grown to an emerging discipline under the forms of LL, which is a relatively new one. It includes widest variety of forms, mode of communication and conveys symbolic messages through the landscapes. The term of "linguistic landscape" (Blommaert, 2012) includes all the linguistic features seen in the writing of public sphere which include any visible and salient written sign, symbol andpainting found on public spaces. In this study, the LLrefers to the sociolinguistic context of the Kathmandu Valley.

\section{Linguistic features in graffiti}

The use of increasing multimodal texts in graffiti and in advertisements is constantly changing today for different purposes. Sheivandi, Taghinezhad, Alishavandi, and Ranjbar (2015), for example, mention that graffiti as a mode of linguistic communication within a community setting which includes the specific linguistic level and artistic way to express the message. Moreover, linguistic analysis provides a source of data which can include grammar, morphemes, and lexical words as well as discourse patterns where communicating strategy is involved. If we look at graffiti, it becomes clear that various linguistics patterns have been employed by artists, similar to those in poetic texts. In the graffiti writing, various rhetorical devices have been used. The advantage of the rhetorical devices (rhyme, satire, assonance) is their rhetorical effect. They help the readers better remember its language and meaning at the right moment.

The graffitists can choose noun, verb, adjective, adverb, compound words and other words as per the purpose and need of the graffiti writing. Particular words are chosen to convey desired meaning. The choice of lexemes in graffiti can help to increase the impact on the readers. Similarly, graffitists use rhetorical devices to communicate their ideas. They use words in a certain way to convey meaning or to persuade (Albashir and Alfaki, 2015) readers and audiences. Certain rhetorical devices are used asways to evoke emotions on the part of the readers and audiences, for instance, graffitists can use metaphor, simile, rhyme, repetition, alliteration, assonance, ellipse, satire and other rhetorical tactics to draw the readers' interest and attention. Likewise, graffitists employ different sentence patterns to communicate their ideas and pull attention of readers. For example, they use declarative, imperative, simple, interrogative and exclamatory sentences to convey their messages. 


\section{Methodology}

This study adopted MDA which deals with linguistic and visual analysis. This approach is one of the branches of Critical Discourse Analysis (CDA) which offers multiple modes of communication. It has been taken as a new area of research after the work of Halliday's Systemic Functional Grammar (2004) and 'Reading Images: The Grammar of Visual Design' by Kress and Leeuwen, (1996). Multimodality is the study of how multiple communication modes combine to make meaning such as language, gesture, proxemics, images, color, layout etc. It makes meaning through the combined use of various semiotic resources like graffiti's visual imaginary. Jewitt (2009) proposes "multimodality approaches representation, communication and interaction as something more than language" (p. 1). Jewitt further writes, modalities, or modes, are "semiotic resources for making meaning that are employed in a culture - such as image, writing, gesture, gaze, speech, posture" (p. 1). Using MDA approach, this study deals with the various interpretations of multimodal features of graffiti observed in the Kathmandu Valley. Multimodal analysis helps to analyze the field of practice (such as graffiti) where meanings are systematically made through the use of stylistic patterns, for example, with the use of symbol, color, sign (Kress, 2010). In fact, MDA provides a tool for analyzing and describing the various semiotic resources that graffiti writers and urban artists use to communicate and represent on their environment and other graffiti works. Furthermore, it emphasizes on different roles and functions of images, use of space, gestures and gestural marks used in graffiti (Jewitt, 2009).

For this study, in total, 300 pictures of graffiti were taken, appearing in the Kathmandu Valley. Among them, 44 pictures were selected as sample of the study through purposive sampling procedure. Observation was used as research a tool for data collection. Samsung A5 and Samsung J7 pro cellphones were used for documenting the graffiti. With the help of the cellphones, all photographs were documented. After gathering the graffiti, all the pictures were arranged and rearranged for developing themes. And the graffiti were analyzed and described developing multiple themes.

\section{Results and discussion}

The data have been analyzed developing major themes: content, language and linguistics aspect. Along with these themes, the meanings of the graffiti have been interpreted.

\section{Contents represented in graffiti}

The selected graffiti of this study revealed that graffiti are commonly found in public spaces like wall of the Zoo, a public wall, street wall, Chautaraa raised platform with a tree (s) for rest, a public toilet, a bridge, a building constructed by the government etc. in the Kathmandu Valley. Public buildings allow more access to more diverse 
readers where graffitists find more convenient opportunity to communicate their messages to their readers. In the graffiti, it was found that they were represented in various themes ranging from language, politics, culture, environment and health, gender discrimination etc. Graffiti writing with similar messages have been grouped together and discussed below.

\section{Cultural identity}

The graffiti collected from various streets of the Kathmandu Valley showed the diversified cultural practices. It was found that ethnicity, religions, and cultural diversity were popular topic among graffitists to reveal their selfidentity through their arts in the public spaces. The graffitists also wanted to show humanity, brotherhood, culture, and religions followed in the country.

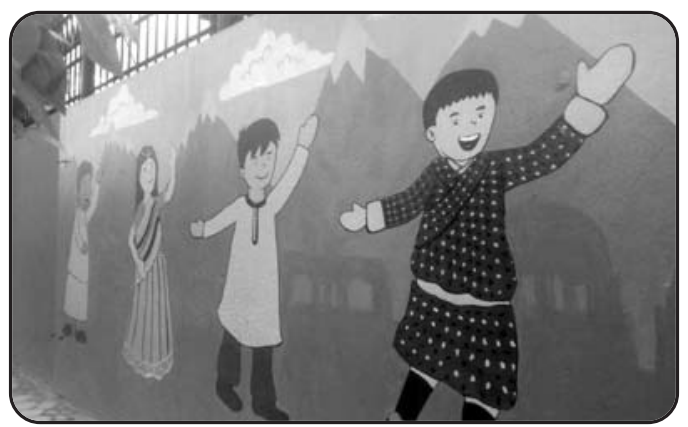

Fig 1: UN Wall Lainchour

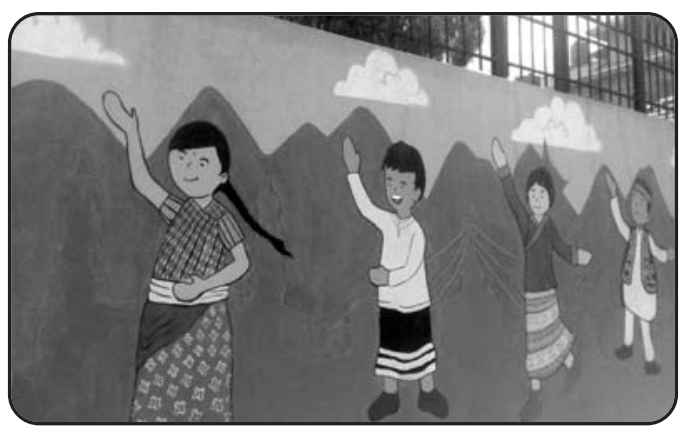

Fig 2: UN Wall Lainchour

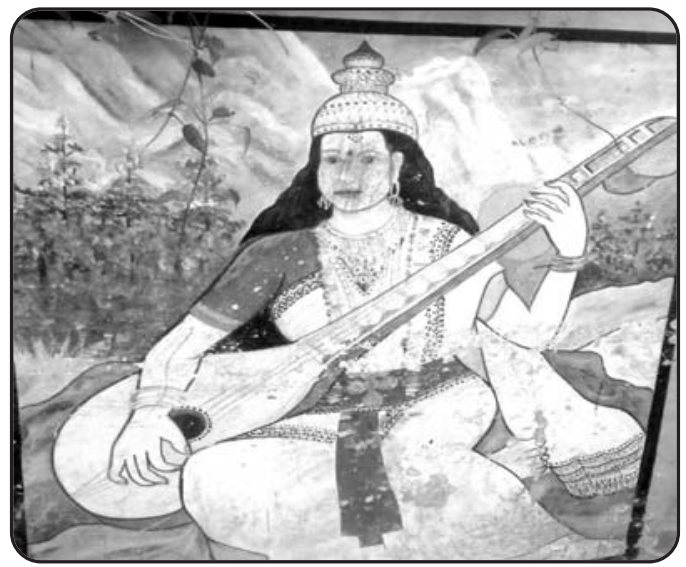

Fig 3: Lazimpat Street

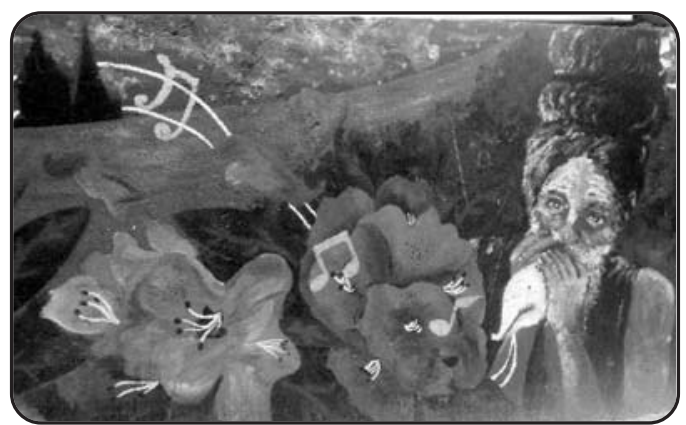

Fig 4: Durbar Marg Street 


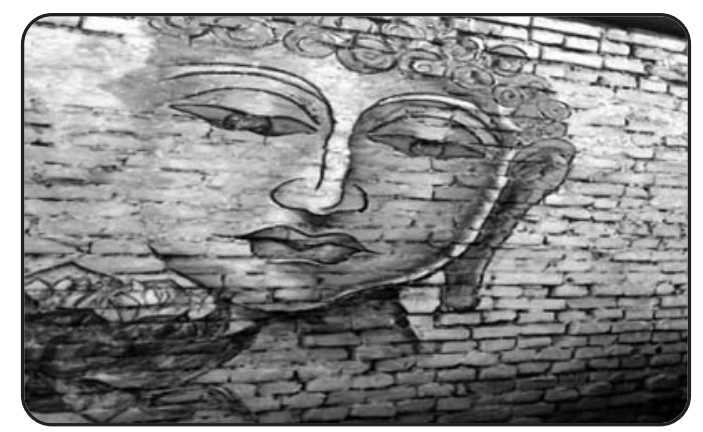

Fig 5: Lazimpat Street

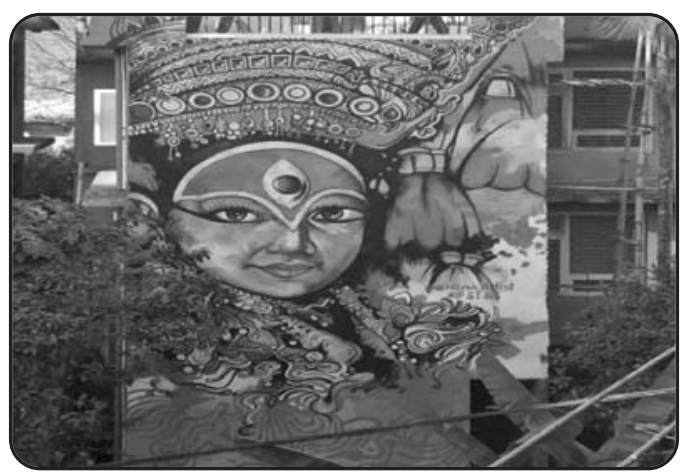

Fig 6: Wall of Neelgiri High School

Similarly, the graffiti figs. 3, 4, 5, and 6 were also related to the local festivals which are celebrated by the Nepalese people. Graffiti writing in the most of the streets that the researchersvisited gave information about the local culture that people are experiencing. The above graffiti reveal the festival of Basanta Panchami, Maha Shivaratri, Buddha Jayanti, and KuramiJatra respectively which people celebrate at a time in a year.

\section{Gender equality}

Gender equality is another theme where graffitists create graffiti to communicate

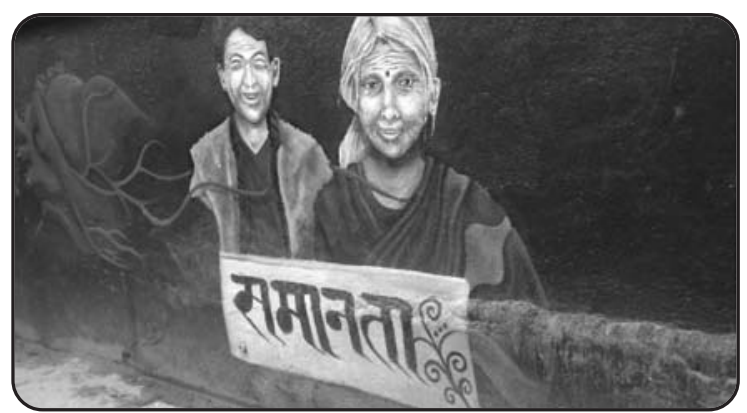

Fig 7: Wall of Himalayan Hotel, Kupondole, Lalitpur

messages for equality using multiple modes. They used graffiti as a strategy for integrating the gender issue. Graffitists write graffiti to address the issue of gender gap and focus on human rights for all. The collected data shows that graffiti was drawn to ensure the fairness between men and women, and appeal for equal treatment between them. Here is an example.

The above graffiti illustrates the incorporation between writing and painting which combines the various semiotics for meaning making. It constitutes the word 'समानता' directly connected with the symbols nerves and heart of men and women. According to the symbol application, there is no difference between men and women in terms of caste, gender, religion yet all are equal by blood and heart. Here, it also seemed to appeal for equal treatment between male and female in the society. Some of the graffiti which reflects gender equality are: 


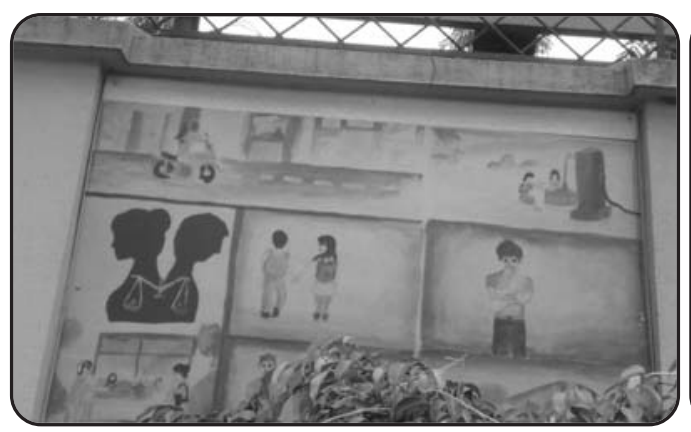

Fig 8: Pulchowk Street

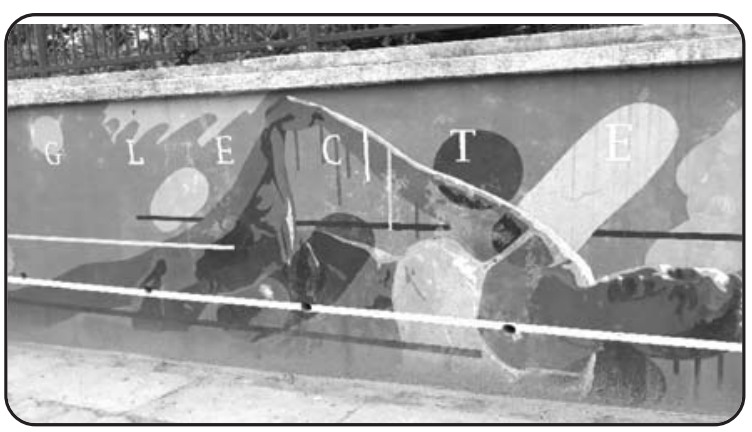

Fig 9: Pulchowk Street

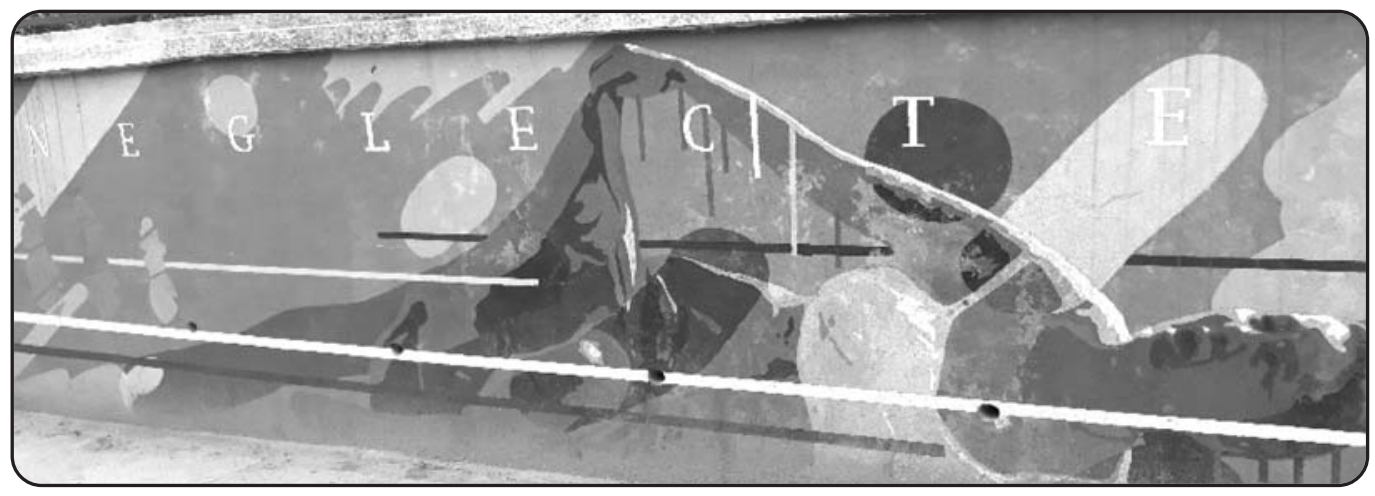

Fig 10: Wall of Himalayan Hotel Kupondole, Lalitpur

Similarly, this image was captured from the wall of Himalayan Hotel, Kupandole. This mural represented the great monument of 'Badi Andolan' in 2007 a protest against the government by Badi people demanding for their basic human rights and inclusion. The mural shows the moment where Uma Devi Badi, one of the Badiprotesttors climbed onto the gate of Singha Durbar. This became an iconic picture representing the Badi Andolan. The horizontal lines represent Uma Badi climbing the gates symbolizing the agitation of the Badi people due to the apathy of the government towards their issues. The word 'NEGLECTED' emphasizes the deplorable state of the Badi community.
This mural shows an important historical moment.

\section{Women violence}

Graffitists are interested to reflect a realistic representation of women issues incorporating with different modes to show women's' mental, physical, and sexual abuse experienced in the society. The collected data shows that contemporary issues like violence against women is a matter of interest for artists to raise a voice for the voiceless women and to do something to end horrible abuse. Some graffiti which show women violence have been presented below. 


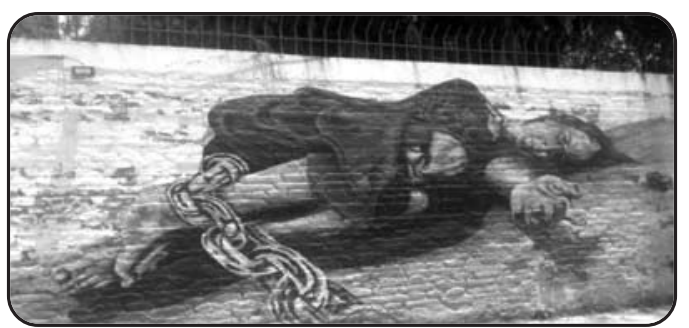

Fig 11: Kupondole Street

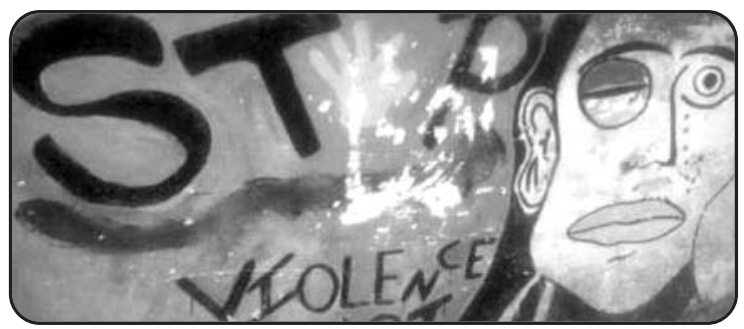

Fig 12: Jamal Street, Kathmandu

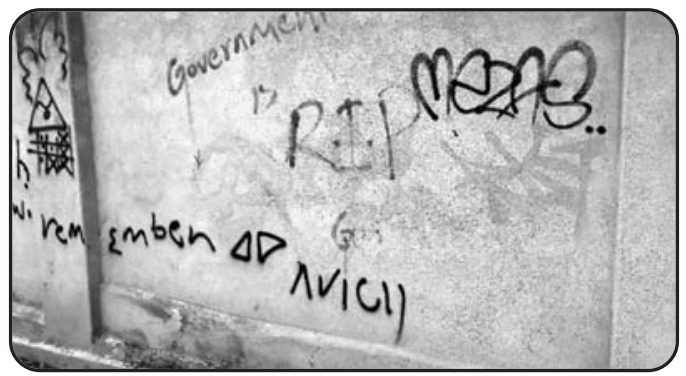

Fig 13: Wall of Zoo Jawalakhel

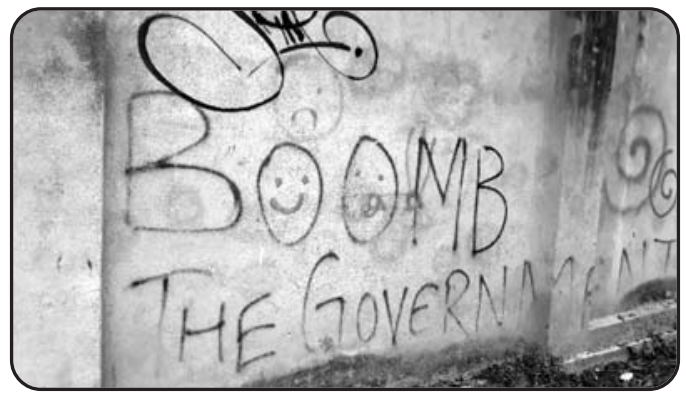

Fig 14: Wall of Zoo Jawalakhel

This above graffiti were captured from the wall of Zoo at Jawalakhel. The sentences like Boomb the government', 'Government is R.I.P.' obviously reflect a negative reaction and state the sense of dissatisfaction towards recent governmental policy. In the first graffiti, though there is an error in the spelling of the word 'boomb' instead of bomb, the message is passed across. Similarly, the second graffiti also seemed to address the feeling of being disappointed by current governmental activities. It seems that political activities are common topics 
for discussion among the public who have knowledge about politics.

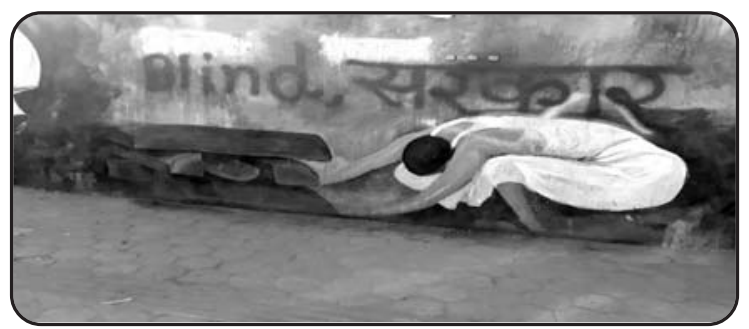

Fig 15: Kantipath Road

Similarly, this graffiti was collected from the wall of a newly constructed building of Bir hospital at Kantipath road. The graffitists appeared to show dissatisfaction with the current government in case of Nirmala's rape. Based on the content of politics, they wanted to satire the government of Nepal being blind during the decision making process for 'Nirmala's Justice.' In this graffiti, Blind;/sf/ was written which again directed to the administration of government as a complaint to do something to offer justice to a marginalized group of people too. By the above graffiti writing, it can be concluded that it is being used to express political non-conformity, social alienation, and anti-system thoughts (Chaffee, 1990). The findings are in line with Farnia's (2014) and Morva's (2016) findings which found graffiti writing as a reflection of public concern that are of present-day issues. Similarly, the findings corroborate Pietrosanti's (2010) and Stampoulidis's (2016) results that revealed graffiti as a means of showing the recent rebellion and rights movements, as well as ongoing political disorders.

\section{Language and linguistics aspects in graffiti}

The collected data shows that graffiti have multiple landscape categories within a single graffiti such as pattern of writing, multilingualism, words with image and colours. Graffitists have conveyed symbolic messages through the linguistic landscapes. Similarly, written patterns of graffiti includes inscription in the forms of stylistic word writing, sentences and pictures together which is quite different from formal inscription.

\section{Bilingual landscape}

In the graffiti writing, a bilingual landscape can be observed. The graffitists have strived to show the current linguistics landscape in Nepal. Here is an example of bilingual graffiti.

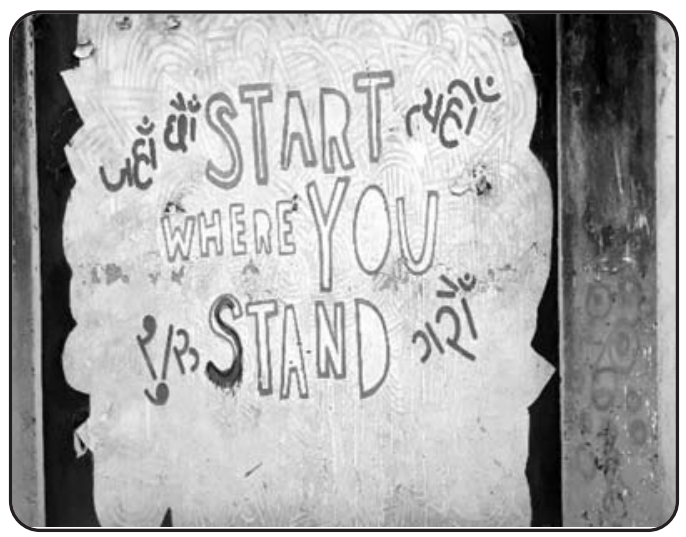

Fig16: Wall of Zoo

This graffiti was picked out from the wall of Jawalakhel Zoo. In this case, the graffiti on display on the wall is in more than one language and, more specifically, the languages are equally presented: each of these languages thus receives equal value in its use. The language used 
here is English and Nepali (जहाँ छौँ त्यही सुरु गरौै) START WHERE YOU STAND. However, the English has been presented as a dominant language that displays the content more clearly than Nepali. In the example, all Nepali words are written in the side of the phrase 'START WHERE YOU STAND' whichiswritten in the middle of the graffiti with all capital letters. In English, capital letters are used when something is more focused on the content. The colors of written words also vary from one another. It is found that the use of English in graffiti has been growing; graffitists use English as a well-standard language to communicate with their graffiti readers.

\section{Writingpatte}

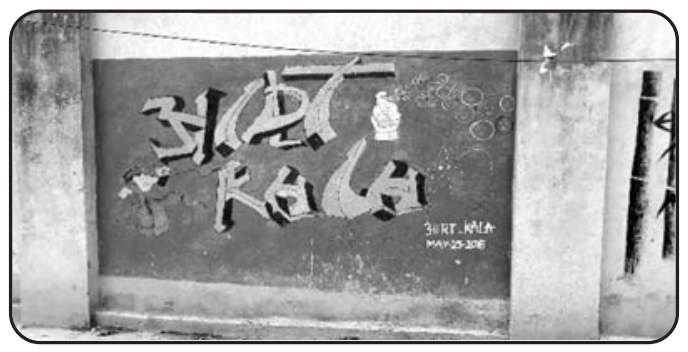

Fig 17: Jawalakhel

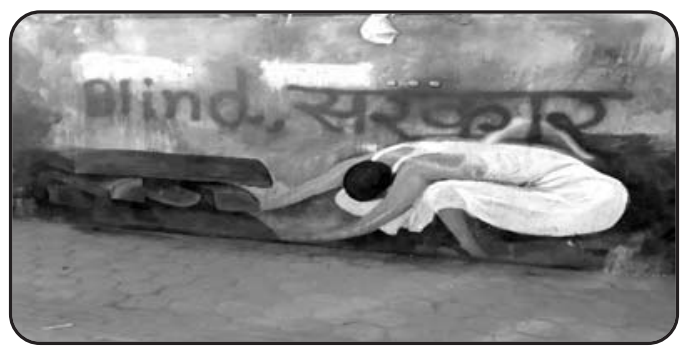

Fig 18: Kantipath

Similarly, looking at the above two graffiti which were captured from the streets of Kantipath and Jawalakhel respectively, we see other evidences of linguistic landscapes. It is evident that graffitists want to attract their readers by using stylistic writing patterns in the streets. In the first photo, only the two words have been written with three different forms (cfRT KALA). The first letter is written in Nepali and the next font of letter which is written in English to complete the full word. Likewise, another word is written in Roman script. The words shown in the photo displayed an artistic style of font size in Nepali, English and Roman scripts. In the second photo, English script seemed more dominant as it is placed strategically on the left side of the graffiti. The English word 'Blind' is an adjective which is used to give a description about the issue and create a good impact on the audiences. In comparing both examples, graffitists have favored stylish writing patterns to communicate the message more clearly to their readers. Here are some other examples of stylish patterns where some words are highlighted by writing in capital letters, some letters having been made bigger than other letters. However, the crucial information appears mostly in English because of the need to address all the readers.

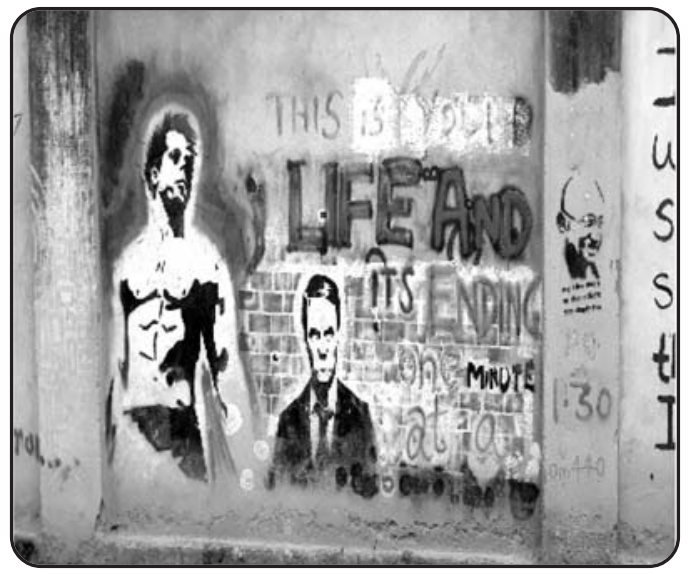

Fig 19: Jawalakhel 


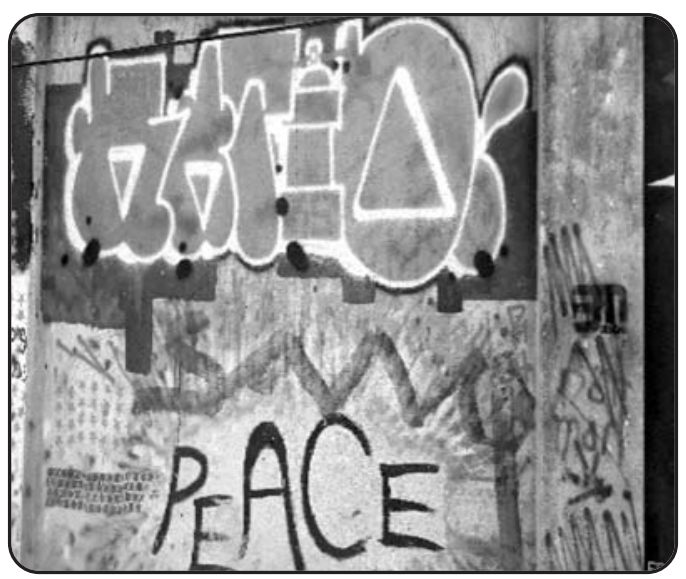

Fig 20: Jawalakhel

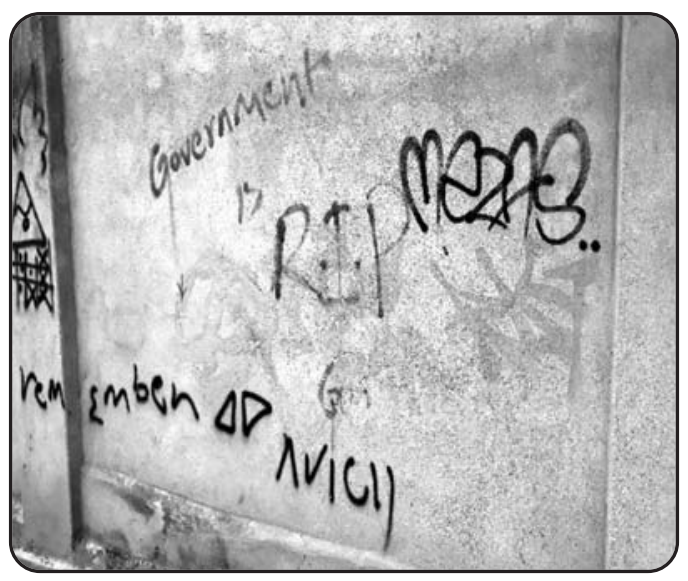

Fig 21: Jawalakhel Street

\section{Words with images}

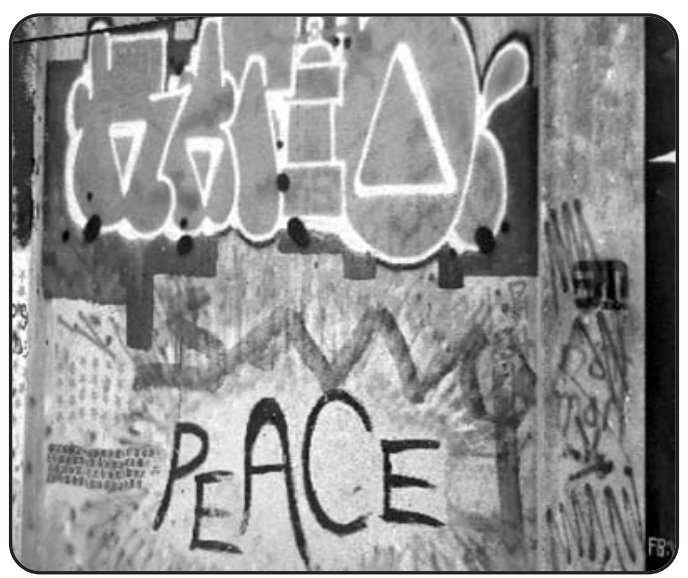

Fig 22: Jawalakhel Street

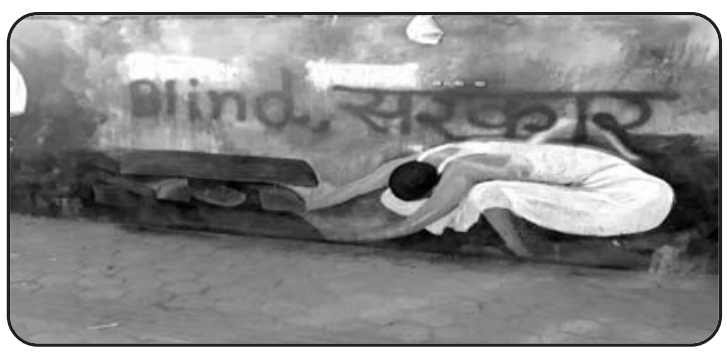

Fig 23: Kantipath

These graffiti were captured from the zoo of Jawalakhel and Kantipath respectively. All the wall graffiti were made of the same materials; painting with different colours. The portrayal of these images gives an impression that the graffiti that will be visible for a long time. The wording of this graffiti indicates the political condition of the country. This sign indicates the community desires to create peace in the country. Artistic styles of word writings and colours were used to make the graffiti more attractive whereas another photo shows the aggressive reaction of people towards governmental activities. The symbol of a human skeleton perhaps indicates the dominant people who have political power and the man with white dress identified as marginalized people who became the victim of power abuse. Both graffiti constitute the image with language which contributes equally in meaning-production.

These photos were the evident of a linguistic landscape that has been recognized on the streets of the Kathmandu Valley.

\section{Use of language}

The study established that language and linguistics is one of the themes found on the walls of Kathmandu Valley where 
graffitists used different languages and dialects for communicating their messages. Halliday (1978), in his 'Social Semiotics', writes that language is believed as one of the modes for the meaning-making process. Our collected data show that graffitists applied various languages ranging from local vernaculars to Nepali and English in order to address foreigners as well as highly literate people for communicating their messages, thoughts and opinions. Mainly, graffitists use the English language in public spaces to create a positive impact and to communicate to global audiences. They are also written in varieties of local language which help us to understand what is being communicated.

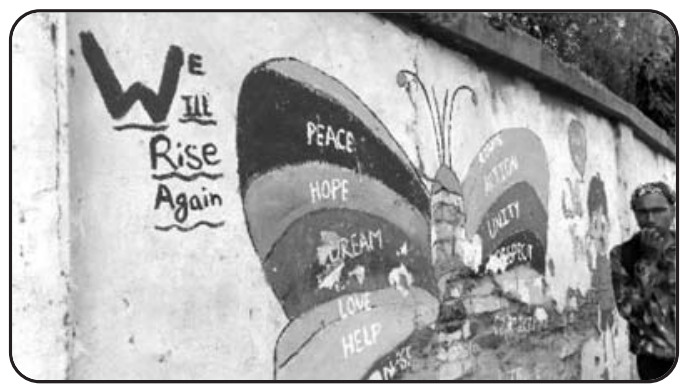

Fig 24: Lainchour Street

The given graffiti reflects that graffitists used words, sentences, combinations of words and drawing simultaneously to communicate their message. Graffitists wrote graffiti by using the full simple sentence: We Will Rise Again, words in English: PEACE, HOPE and images of a butterfly to communicate their thoughts and feelings. The graffiti contains English words and sentences, as well as images. Graffitists usually used full sentences when they wanted to make their messages as clear as possible to their intended readers. Here, graffitists wanted to motivate earthquake victims to have patience and hope for rising again as soon as possible. It also appears to build the feeling of unity which was reflected by different colours that perhaps encourage the different castes and ethnicities to overcome such a natural disaster.

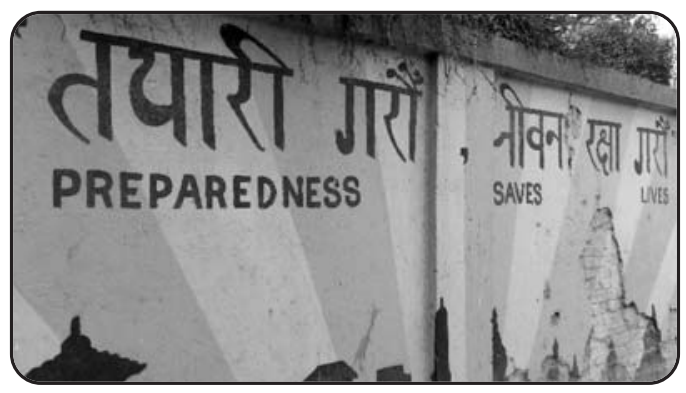

Fig 25: Lainchour Street

Similarly, this graffiti was captured from the street of Lainchour. The graffitists used another full sentence by using two different languages simultaneously to make the reader aware of upcoming devastation. The writer appeared to encourage other people not to be careless about the devastation but to be prepared for it.

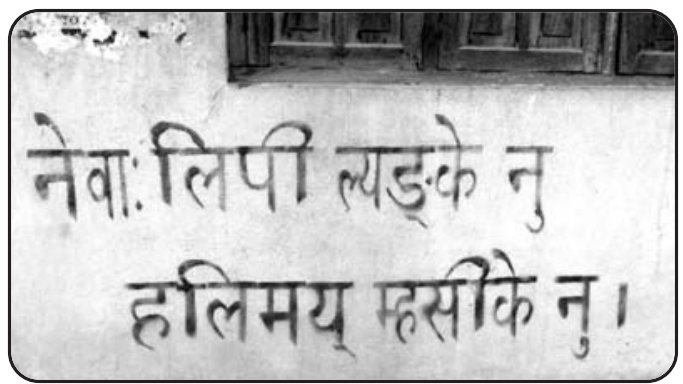

Fig 26: Behind the Kritipur Hospital

This graffiti was taken from the street of the Kritipur. The diverse writing patterns suggest that graffiti is a communication that needs no protocols: 
one can write anything one wants on the wall. The graffitists have chosen to express their feelings in Newari script rather Standardized Nepali Language. They have written (नेवा: लिपी ल्यङ्के नु हलिमय् म्हसीके नु). This means use the Newari script and promote it for further development. This is because the graffitist might be of Newari ethnicity and wants to encourage local graffiti readers to use Newari script and promote it for further development. This graffiti also reinforces the idea that using such language for communication can motivate the reader to learn and understand the value of such local language.

The analysis of data shows similar information related with the theory of Halliday's Social Semiotics (1978), which says that language is believed to be one of the modes of the meaning-making process. The analysis of this study also shows that, graffitists applied various languages including local vernaculars, Nepali and English in order to address foreigners as well as highly literate local people for communicating their messages, thoughts and opinions.

\section{Linguistics aspects of graffiti}

This presents the analysis of linguistic features in terms of words choice, rhetorical devices, and syntactic features. The single graffiti has multiple features.Therefore, we have classified those graffiti under the various topics.

\section{Word choice and word-forms}

A careful word choice is an important part of any type of writing, especially content writing. Selecting precise words in text increases the impact of the text on the audiences. The data show that graffiti have included nouns, adjectives, and verbs. Nouns are used to identify some persons, things and states. Here are some examples:

\section{Use of nouns}

The main aim of writing graffiti is to communicate something to intended audiences. So, graffitists' use a very short and attractive style of writing which conveys the message in an artistic way. In graffiti, nouns are used to communicate what is happening. Nouns are used to identify to some persons, things and states. The collected data show that graffiti involves heavy used of nouns. It indicates person, things and states which permit people to understand the message more clearly. Here are some examples:

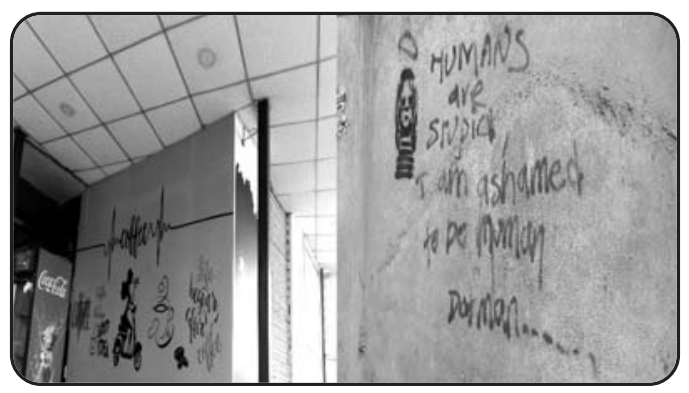

Fig 27: Kritipur Fig 28: Street of Bhaktapur

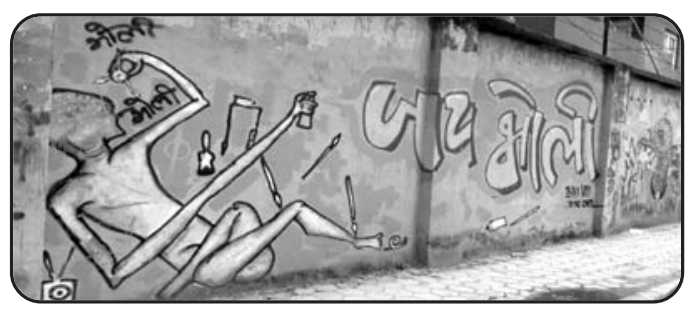

Fig 29 : Wall of Zoo, Jawalakhel 
This photo was taken from the wall of restaurant of Kritipur. The use of noun such as 'Coffee', Life can be seen in this graffiti. The purpose of this graffiti is to attract the people to have a coffee. The English language appears as the dominant language on the wall where nouns like coffee, life words are used. In other photos, words like 'human', 'dotman', 'government', 'bomb' 'Oli' are used to show the person, thing and state in the sign.

\section{Adjectives}

The main aim of writing graffiti is to communicate with readers as much as possible. Graffitists use very short and attractive language which presents the useful information about the different issues. In the graffiti, adjectives are used to give a description about the issues and it creates a good image of graffiti which causes readers to understand and realize the contemporary condition of the Nepalese society. In this regard, Kaur et al. (2013) argue, adjectives usually spread positive emotion, fantasy, dreams and desires in people's minds.

The collected data show that graffiti involve a heavy usage of adjectives. Generally, adjectives highlight the best or negative qualities of the issues and message which expand emotional appeal, creating a more convincing message. Here are some sample examples:

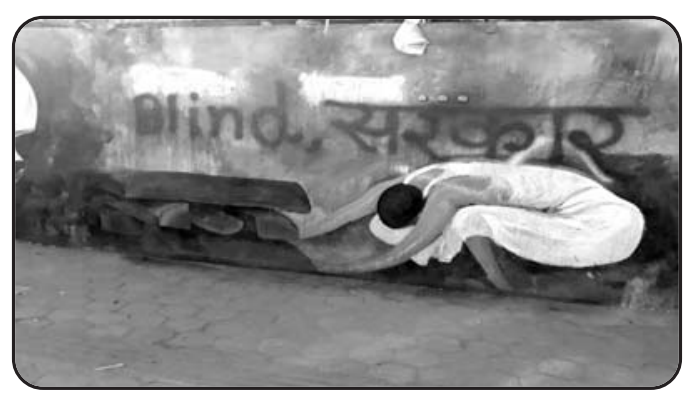

Fig 30: Kantipath Street

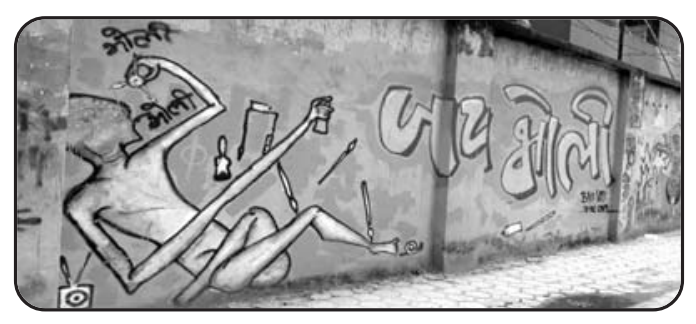

Fig 31: Jawalakhel Street

The use ofadjectives can be seen in the graffiti. These are the graffiti that have a content of politics where graffitists were complaining that the government is not providing effective administration service. The phrase 'Blind सरकार' contains the one adjective 'blind'. Simply, the word blind means unable or unwilling to perceive or understand reality. By using the word 'blind,' graffitists seemed to complain that the administration of government is being irresponsible towards public problems. Here, the word 'blind' appears to capture more attention of graffiti readers to make them aware of politics. Similarly, the next graffiti also has one adjective of Nepali, 'भोली' which means 'tomorrow' or 'the day after today'. Graffitists have used this word symbolically to satirize the administration of 'Oli sarkar' to provide the governmental service on time. 


\section{Verb}

In a sentence, a verb can be defined as one of the important parts, which is used to demonstrate an action or state of being. The verb is a main component of the predicate without which there would not be a sentence. Many graffitists use present tense to interact whatever they are saying, which makes positive impact on their audiences. The collected data shows that in graffiti present tense is mostly used. Here is an example:

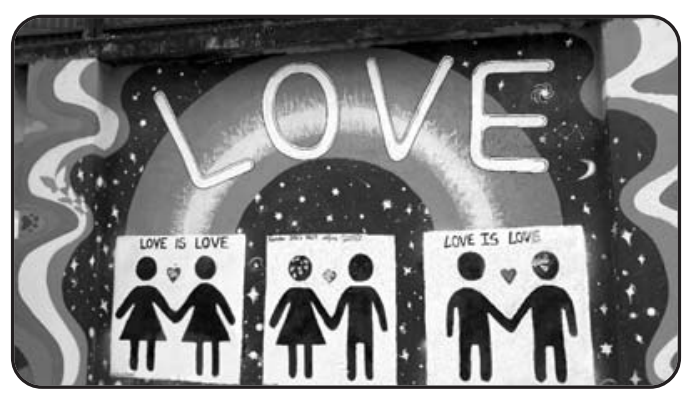

Fig 32: Lalitpur Street

This graffiti was found scribbled on the wall of the Jawalakhel zoo. The graffiti has a meaning of love which does not specify any gender. The use of simple present tense can be seen in the sentences which says 'love is love', 'gender does not define the love', 'love is love'. In these sentences the verbs 'is' and 'does' are the used to show present time, and they are used to show that the actions have happened at present. Similarly, the graffitists use the present tense (the verbs) to convince readers and audiences since the tense is used to express truth.

\section{Rhetorical devices}

This section deals with the rhetorical devices found in the graffiti writing:

\section{Metaphor}

Metaphor is a part of figurative language which describes an object by referring to another object that is considered to have a similar kind of meaning to the object being described. It is used to create direct impact on audiences. The collected data show that metaphor is used on graffiti art to attract people's minds. Here is an example:

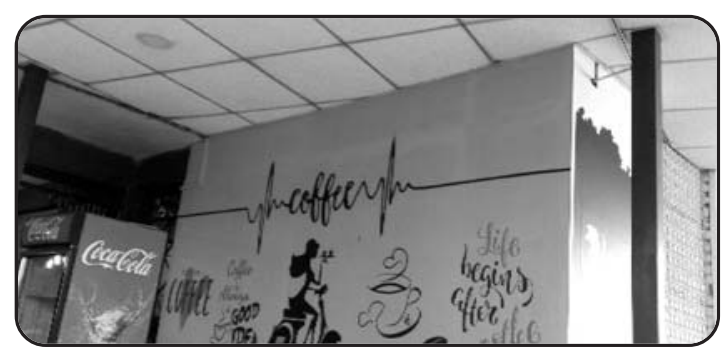

Fig 33: Kritipur Street

The above given graffiti was written on the wall of a restaurant which is about the coffee where graffitists used the metaphor 'Coffee is always a good idea'. Here, the author of this graffiti has drawn the beautiful lady who is riding the Scotty by one hand and holds the cup of coffee in her other hand. In her upper side, the word 'Coffee' is written in stylish way with an imagined EKG trace of a human heartbeat. The graffitists used the metaphor sentence to encourage the people to have a cup of coffee, that this is the best way to start the day. Here, coffee is compared with a good idea (which is bold by the black colour) i.e. having a cup of coffee is the best option for people to start their day. 


\section{Rhyme}

Rhyme refers to the repetition of the sound especially the vowel in a line or a verse form of language. It is often use to create a melody in a language which attracts people to listen or read more interestingly. The captured data also indicate that there is excessive usage of rhyme on the streets of Kathmandu valley. Here are some examples:

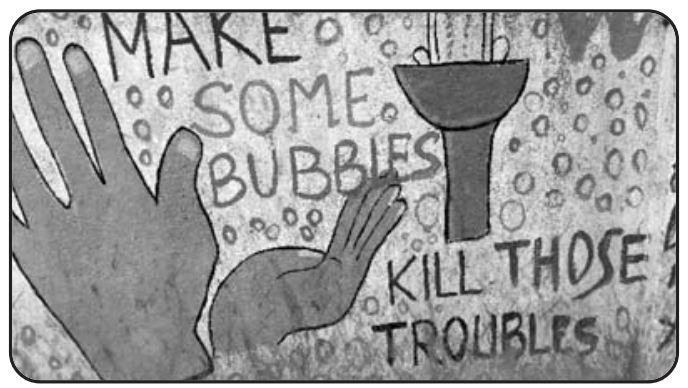

Fig 34: Jamal (Kathmandu)

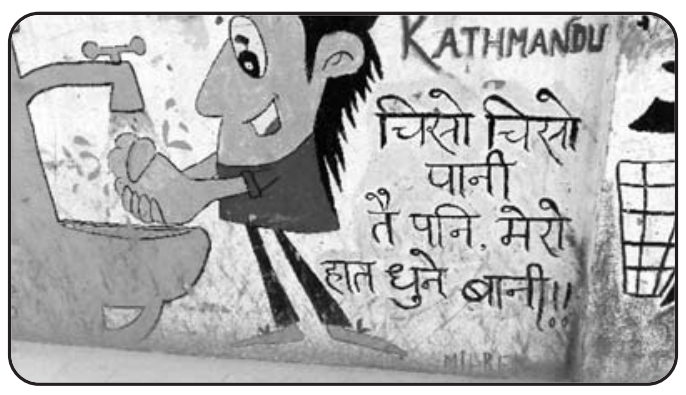

Fig 35: Jamal (Kathmandu)

The above given graffiti was written in form of rhyme which is one of the feature of rhetorical devices. The data show that it is a kind of trend to use such rhyme forms in both Nepali and English, such as MAKE SOME BUBLES KILL THOSE TROUBLES in street graffiti to attract readers. In the first graffiti, the Nepali inscription with melody rhyme on the wall was displaying which communicated the special habit of good hygiene. It argues that people should wash their hands all time. We can also assume that the graffiti artist used the rhyming technique to provide us suggestions to follow the above rules for healthy lives. Similarly, the second sign illustrated the same theme with English rhyme inscription. These graffiti provide significant information as graffitists use such a technique to attract their readers and made graffiti memorable.

\section{Satire}

This is a way of criticizing a person and idea or an institution using humour to show their faults or weaknesses. The collected data shows thatsatire is being used in graffiti. Graffitists demonstrated the socio-cultural and socio-political messages of the society by using satirizing sentences with images. It is used as weapon to show someone's weaknesses. Here is an example:

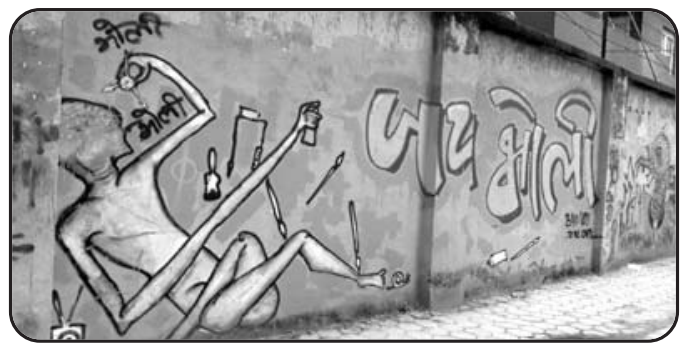

Fig 36: Lalitpur Street

This graffiti was captured from the street of Lalitpur district. While examining this sign, we see that graffitists seemed to satirize the recent governmental staff for not being active. We note that the words 'Jaya Voli' is highlighted with big font size which indicates those who are in power or working at government offices but not doing any action on the spot. It reflects those who are giving priority to postponing their work. So, the photo 
seemed to satirize the present governmental staff for not doing their work effectively. Moreover, the word Voli and Oli is written in same font with same colour, perhaps satire the Oli leading governmental system for not being responsible to their job.

\section{Ellipse}

Ellipse is an omission of some words to make sentence short and sweet. While omitting some words, the overall message should not be changed. It is a characteristic of graffiti where graffitists use short sentence structure for impacting positively to their people. Here are some examples:

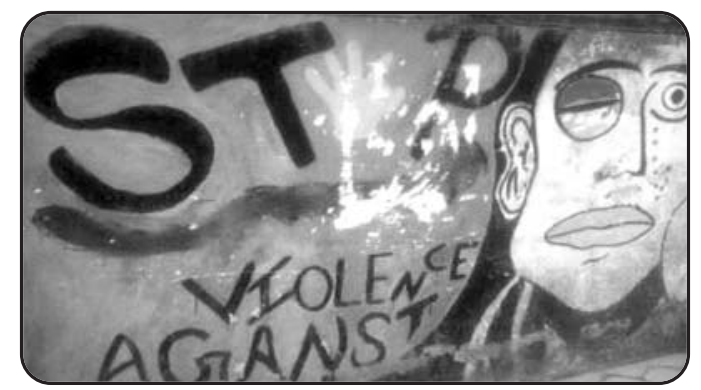

Fig 37: Kathmandu Street

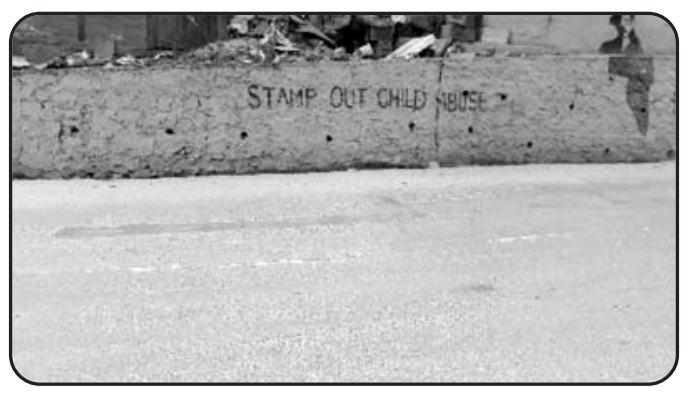

Fig 38: Lalitpur Street

The collected data also shows that graffitists' elide some initial words to make sentence short and attractive. The above given photos were captured from Jamal and Ekantakuna respectively. The use of ellipsis as shown in the sentence of above photos were; 'Stop violence against women, Stamp out child abuse'. In both photos 'We should' subject with modal verb is omitted. However, people understand the message conveyed in the graffiti. So, in ellipsis some words are omitted by keeping the words on graffiti from which the meaning and message can be assumed. The analysis of data indicates that graffiti observed in the Kathmandu valley use features like ellipsis to make message of graffiti short and memorable.

\section{Syntactic features}

In graffiti, varieties of sentences were used interchangeably. The most important structural tendencies used by graffitists have been explored below.

\section{Declarative sentences}

Another linguistic analysis of graffiti is sentence patterns. In the graffiti, language is also one the mode of communicating messages. People use images with language simultaneously to communicate with their audiences. The captured data shows that well composed statement are used by the graffitists to their audiences which have a very deep meaning. Here is an example:

Fig 39: Lalitpur Street

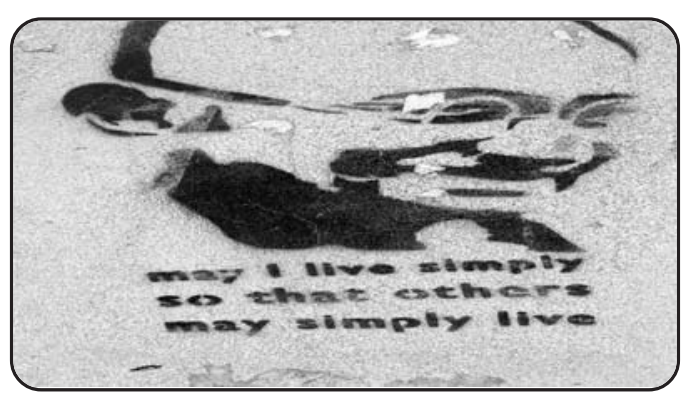


This graffiti is picked out from the streets of Lalitpur. Graffitists have employed the legend's statement 'May I Live simply so that others may live simply' with their images to convey the message. The statement given by a famous face perhaps has more impact on readers. The above given image of Gandhi represents simplicity. The statement given by Gandhi has been written on the wall which has given the message of simple living. Such statements were often observed during the data collection time.

\section{Imperative sentences}

This is another type of sentence pattern which is practiced by the graffitists of the Kathmandu valley. Imperative sentences are used to instruct somebody to do something. The collected data shows that graffitists have used such sentences to attract their reader where they omitted subjects in the graffiti. Here is an example:

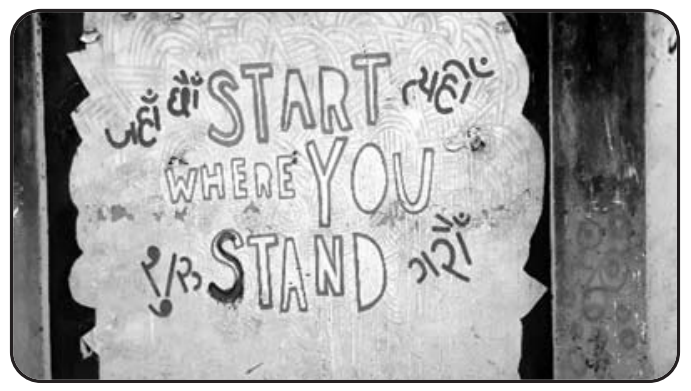

Fig 40: Lalitpur Street

This graffiti is an example of using imperative sentence to communicate their ideas and opinions. The writer of this graffiti wrote 'STAND WHERE YOU STAND' which seemed to tell others that we should be doing something from where we stand so that others might follow us in doing some good works. The above graffiti lacks the subjects, but communicates a clear message to its audiences.

\section{Interrogative sentences}

Interrogative sentences are concerned with question which requires some information on a specific time. The collected data shows that there were numerous photos captured which have interrogative sentences. Here are some examples:

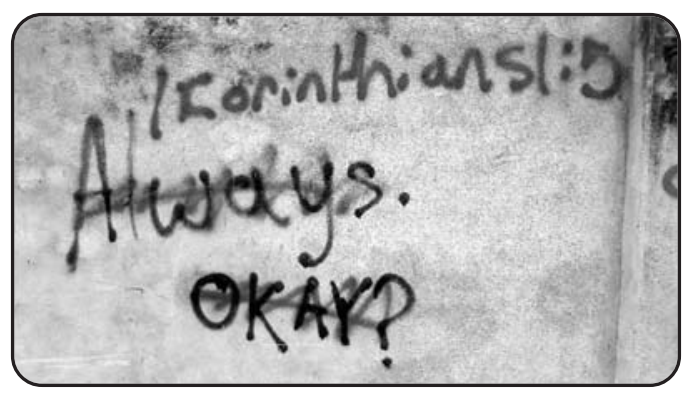

Fig 41: Jawalakhel Street

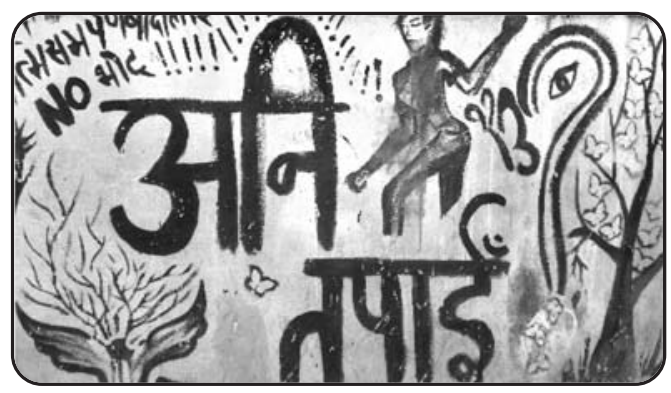

Fig 42: Pulchowk Street

This graffiti were captured from the streets of Pulchowk and Jawalakhel respectively. The authors of these graffito have written Always Okey? (अनि तपाइ?) i.e. and you ? by using interrogative sentence patterns in the graffiti to ask for public ideas or opinions on the particular issue. 


\section{Exclamatory sentences}

Exclamatory sentences are used to express the speakers' impression about something. The collected data shows that graffitists usually used such patterns to attract their audiences. Here are some examples:

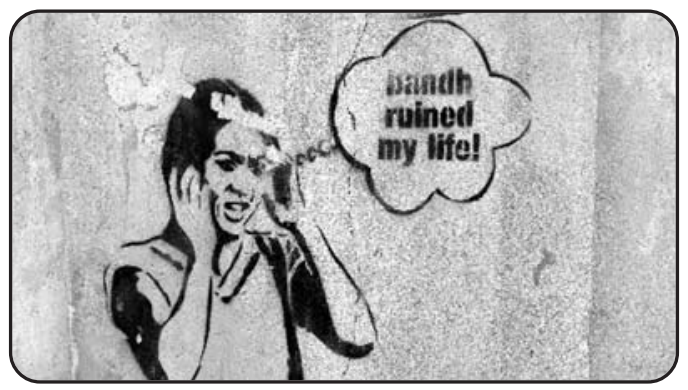

Fig 43: Lagankhel

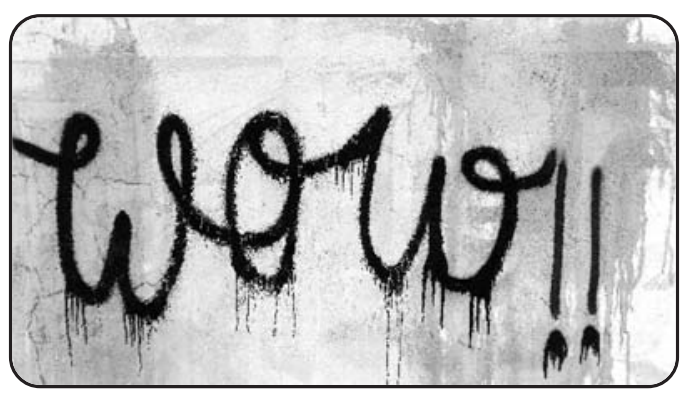

Fig 44: Bhaktapur

In the above graffiti, the first graffiti seemed to be dissatisfaction of people towards the 'Banda' - a strike which forces to close all offices, industries, shops and vehicles in the country. The sentence 'Banda ruined my life'! perhaps indicates the difficulties experienced by lower class people during Nepal Banda. Similarly, the second graffiti 'Wow'!! is the expression of joy seeing something beautiful.

\section{Conclusions and implications}

The present study is a qualitative descriptive study conducted to explore contents of the graffiti and analyse language and linguistics aspects of the graffiti. Based on the findings, it can be concluded that graffiti appearing in the Kathmandu Valley carried multiples contents and varied writing patterns and landscapes and multiple modes in the meaning-making process. The findings show that we are not living only in spoken or written discourse, but other modes like colours, paintings and signs are equally contributing to meaningmaking. Likewise, it is indicated that focusing solely on one mode like written or spoken texts removes the possibility of finding meaning in others forms. Furthermore, the world has been multimodal, where, besides language, other semiotics are constantly used to communicate opinions and thoughts. This study shows that use of multiple modes like words with image, symbols, color stylish writing allows us the possibility of seeing more. And last but not least, this study also identifies that graffiti art is a strong weapon to attract people to interpret meaning from social context. This study indicates that the graffiti appeared in public places should be used to comment on socio-political issues in Nepal, using multimodal modes of communication.

By this study it can be inferred that graffiti writing should be recognized by course designers and educators as important teaching learning materials and that they should allocate an area for graffiti so that students can foster their seeing, noticing, identifying and 
designing skills of graffiti. Further, graffiti should be included in textbooks as students my love colourful images and pictures instead of lecture in the class. Students can get real input or natural process of meaning-interpreting by looking at graffiti materials in the classroom. Students can see a variety of language, script art and colour on the walls. As a result, students can learn multiple modes of communicating meanings, and the importance of writing on walls. Additionally, if graffiti art is used as teaching materials in the classroom, students can develop their critical power of analysing graffiti and can foster their higher order thinking which leads them to see things more critically. As graffiti reflects existing societal problems of the country, the use of graffiti helps teachers to teach their students to identify the grass-root problems existing in the society and makes them aware about social-political issues and problems prevalent in the society. Likewise, graffiti can be used to satire government's action, and thus it can appeal to the government to correct its misdeeds and provide justice to people.

In Nepal, there are a number of graffiti areas that have not still been explored. For instance, in Nepal, Critical Discourse Analysis of Toilet Graffiti, Graffitists Perception of Writing Graffiti: A Narrative Inquiry, Communicative Strategy Used in Graffiti Writings are the some possible areas which have not been reconnoitred yet. Hence, these topics can be doable areas for future researchers.

\section{References}

Abel, E. \& Buckley, B. (1977). The handwriting on the wall: Toward a sociology and psychology of graffiti. Westport, CT: Greenwood.

Albashir, E. H. \& Alfaki, I. M. (2015). An exploration of the rhetorical devices in Leila Aboulela's novel 'The Translation'. American international journal of contemporary research, 5, 1, 29.

Al- Khawaldeh, N. N., Khawaldeh, I., BaniKhair, B. \& Al- Khawaldeh, A. (2017). An exploration of graffiti on university wall: A corpus based discourse analysis study. Indonesian Journal of Applied Linguistics,7, Jordan, 29-42.

Alshreif, N. F. (2016). Multimodal writing: The case of graffiti. Arab World English Journal, 7, 453-466.

Bhusal, A. (2019). Addressing FYC Instructors' Lack of Technological Expertise in Implementing Multimodal Assignments. In Marginalia in Modern Learning Contexts, IGI Global, 166-186.

Bhusal, A. (2010). Genre awareness in the writing center. MA Thesis, Department of English,

Eastern Illinois University, Illinois.

Brett, W., (2011). The writing on the stall: Graffiti, vandalism and social expression. Kaleidoscope, 9, 11.

Central Bureau of Statistics (CBS) (2011). Population census report. Kathmandu.

Chaffee, L. (1990). The popular culture political persuasion in Paraguay: Communication and public art. 
Studies in Latin American Popular Culture, 9, 127-148.

Chiluwa, I. (2008). Religious vehicle stickers in Nigeria: A discourse of identity, faith and social vision. Discourse $\mathcal{E}$ Communication, 2(4), 371-387.

Collins, A. (2018). Graffiti: Vandalism or art? New York: Lucent Press.

Farnia, M. (2014). A thematic analysis of graffiti on the university classroom walls: A case of Iran. International Journal of Applied Linguistics \& English Literature, 3(3), 48-57

Gorter, D. (2006). Linguistic landscape: A new approach to multilingualism. Clevedon: Multilingualism Matters.

Halliday, M. A. K. (1978). Language as a social semiotic: The social

interpretation of language and meaning. London: Edward, Arnold.

Halliday, M. A. K. (1985). Systemic background. In J. D. Benson, \& W.S. Greaves, Eds. Systemic perspectives on discourse, 1. Selected Theoretical papers from the 9, the international Systematic Workshop.

Jewitt, C. (Ed.) (2009). Handbook of multimodal analysis. London: Routlegde.

Jimaima, H. (2016). Social structuring of language and the mobility of semiotic resources across the linguistic landscapes of Zambia: A multimodal analysis. A Master degree Dissertation. University of Western Cape.

Kress, G. \& Leeuwen, V. (1996). In reading images: The grammar of visual design. London: Routlegde.
Kress, G. (2010). Multimodality: A social semiotic approach to contemporary communication. London, Routledge: Taylor \& Francis group. Milton Park,

Leichty, M. (2003). Suitably modern: Making middle-class culture in a new

consumer society. Princeton University Press New Jersey.

Mangaya, H. (2014). A sociolinguistic analysis of graffiti written in Shona and English found in selected urban areas of Zimbabwe. A Dissertation of Doctor of Literature, University of South Africa.

Minchin, M. (2016). Street art in Kathmandu as an activism and social change. Independent Study project (ISP) collection. 2504. (Retrieved on 19 May, 2019 from https:// digtalcollections.sit.edu/isp_ collection/2504).

Morva, O. (2016). The humorous language of street dissent: A discourse analysis on the graffiti of the Gezi Park protests. European Journal of Humour Research, 4(2) 19-34.

Nakarmi, S. (2017). Street art in Kathmandu. Living com. up. Collective, Kathmandu.

Norris, S. (2004). Multimodal discourse analysis: A conceptual framework. In P. Le Vine \& Scollon (Eds.), Discourse $\mathcal{E}$ Technology. Multimodal Discourse Analysis, Washington, D.C. Georgetown University Press, 101115.

Nwoye, O. G. (1993). Social issues on walls: Graffiti in university lavatories. Discourse E Society, 4, 419-442.

Onyango, O. (2016). The talking walls of Rongo University College: A linguistic 
analysis of graffiti use at Rongo University College. International Journal of Academic Research in Progressive Education and Development,5(1), 1-6.

Pietrosanti, S. (2010). Behind the tag: A journey with the graffiti writers of European walls. Amsterdam: University of Amsterdam.

Rubdy, R., (2015). A Multimodal Analysis of the Graffiti Commemorating the 26/11 Mumbai Terror Attacks: Constructing Self-Understandings of a Senseless Violence. Conflict, Exclusion and Dissent in the Linguistic Landscape, 280-303.

Sad, S, N. \& Kaltu, M. (2009). A study of graffiti in teacher education. Egition Arastirmalari- Eurasian Journal of Educational Research, 36, 39-

56.

Sheivandi, L., Taghinezhad, A., Alishavandi, A. \& Ranjbar, S. (2015). Exploring linguistic aspects in Iranians' graffiti. Journal of Applied Linguistics and Language Research. 2(5), 62-73.

Stampoulidis, G. (2016). Rethinking Athens as text: The linguistic context of Athenian graffiti during the crisis. Journal of Language Works, 1(1), 10-23.
Suliman, N. (2014). Critical connection of the graffiti in school. A Thesis Writing: Degree of Master of Arts. University of Toronto, Canada.

Tracy, S. K. (2005). The graffiti method. Australian Midwifery Journal, 18(3), 2226.

\section{Contributors: Jagadish Paudel is}

a faculty member at the Central Department of Education, Tribhuvan University (TU), Nepal. He is currently pursuing his PhD in Rhetoric and Writing Studies at the University of Texas at EI Paso, US. He has completed his M.A. and M. ED. in English from TU. He has worked in the field of ELT for more than a decade, and has presented his research in national and international conferences. His areas of interest include critical pedagogy, learner autonomy, and rhetoric and writing studies.

Pratiksha Neupane has an M.ED. Degree in English Education from Tribhuvan University. 